Original Research Paper

\title{
Effectiveness of Disinfectants on Environmental Multidrug Resistance Contaminants Causing Skin Abscess in Farm Animals
}

\author{
${ }^{1 *}$ Sultan Farag Nagati, ${ }^{2}$ Soumaya S. A. El Shafii and ${ }^{3}$ Shaimaa R. A. Abd El Mawgoud \\ ${ }^{I}$ Department of Bacteriology, Animal Health Research Institute (AHRI), Agriculture Research Center (ARC), Egypt \\ ${ }^{2}$ Bacteriology Department, Equine Bacterial Diseases Unit Animal health research institute (AHRI), \\ Agriculture research center (ARC). Egypt
}

Article history

Received: 05-05-2021

Revised: 01-07-2021

Accepted: 03-07-2021

Corresponding Author: Sultan Farag Nagati Department of Bacteriology, Animal Health Research Institute (AHRI), Agriculture Research Center (ARC), Egypt Email: sultan_farag99@yahoo.com

\section{Introduction}

Infection of farm animals with abscesses is detrimental to livestock due to the enormous economic losses to animals, meat, milk production, skin and wool production accompanying this affection. Mostly, the distribution of wound is the normal continuity of body structures by physical means (Devrajani et al., 2010). Wounds were identified into three types: 1- Incision wounds, which occur due to sharp tools and if there is accompanying

\begin{abstract}
Resistance to antimicrobial agents is recognized as a growing problem for different farms and infection of farm animals with abscesses is detrimental to livestock due to the enormous economic losses. This study aimed to find out the bacterial infection of some cases in farm animals suffering from wounds and abscesses in Fayoum Governorate, Egypt and Related Antimicrobial Resistance (AMR) procedures and technical investigations focused on disinfectant effects or the effects of AMR on bacterial persistence. The samples were collected from 130 different animals (24 buffaloes, 6 cows, 35 sheep, 40 goats, 10 camels and 15 donkeys). By bacteriology examination, eight isolates $(33.3 \%)$ of Corynebacterium pseudotuberculosis biovarequi (C. equi) was isolated only from buffalo with edematous skin lesions (OSD), while Corynebacterium pseudotuberculosis biovar ovis (C. ovis) were isolated from sheep and goats with caseous lymphadenitis lesions in a rate $28.6 \%$ and $27.5 \%$ respectively. On susceptibility test against antimicrobial agents. Pipracillin-tazablam was the best of choice for Pseudomonas aeruginosa and C. equi (20\%).The result showed the bacterial growth at OD595 after treatment with Povidone-iodine (PI) $10 \%$ at different time intervals, where all types of isolates showed the lowest growth after $24 \mathrm{~h}, C$. ovis showed the lowest bacterial growth, while the $C$. equi showed the lowest bacterial growth with $\mathrm{H}_{2} \mathrm{O}_{2} 1 \%$. Conclusion: Caseous lymphadenitis remains an important challenge for the sheep and goat industries. C. equi also plays a role in buffalo raring and caused edematous skin disease which affects milk and meat production. The high resistance of both $C$. ovis and C. equi to antibiotics and disinfectants reflected the necessity to adopt control measures. MRSA, as well as PDR Pseudomonas aeruginosa, were observed animal wounds which prove the bad hygiene. Increasing contact time is more effective against microbes.
\end{abstract}

Keywords: Environmental Contamination, Abscess, Farm Animals, Multidrug Resistance Bacteria, Disinfectants tissue that tears the wound, it is known as a torn wound.2Abrasions, which are defined as damage to the surface of the skin due to friction and are characterized by superficial bruises and a loss of varying thickness of the superficial and subcutaneous layers3- Puncture wounds, which are open injuries in which foreign substances and organisms are likely to enter deep into the underlying tissues. Timothy and Bruno (2021) classified wounds to four classes according to the cleanliness and condition of wounds class (1) wounds are clean, class (2) wounds are 
clean and contaminated, class (3) wounds are be contaminated and class (4) dirty infected wounds. They often engage in long hours and when released, they are left to surf and feast on the less nutritious litter. This has been linked to a potential negative impact, particularly on their well-being and health (Mekuria and Abebe, 2010; Bogale et al., 2012)

Donkeys (Equusasinus) are among the early domesticated equines that have been a heavy beast for thousands of years. There are currently about 44 million donkeys distributed all over the world. In Africa, the donkey population is considered by 13.7 million (Gichure et al., 2020). Despite increasing mechanization worldwide, donkeys still feature prominently in the farming systems of numerous developing countries. (Shrikhande et al. 2009; Molla and Gondar 2015). The donkey are still one of the most underappreciated animals and an important project, as it plays a major role in the agricultural economy of the developing world involving Africa (Ahmed et al., 2008). Donkey skin wounds are a proper habitat for the growth of microorganisms especially in saddle ulcers because they accelerate the risk of infection by providing ideal conditions for the growth and reproduction of some microorganisms (Devrajani et al., 2010). Caseous lymphadenitis in sheep and goats is a chronic and subclinical disease all over the world, presenting high animal and flock prevalence's. Pseudo cystic tuberculosis, affects sheep and goats and can also infect cattle and horses and rarely in humans; so, it is considered an occupational animal disease. The microorganism was isolated from other species, including pigs, buffaloes, deer, porcupines, llamas, camels and laboratory animals (Dorella et al., 2006. In Assiut Governorate-Egypt, $C$. equiand $C$. ovis were isolated by $72 \%$ and $28 \%$ respectively from buffaloe and cows (Arafa et al., 2019).

Corynebacterium pseudotuberculosis is categorized by two biovars (Sellyei, et al., 2017) the biovar Ovis, which at most affects goats and sheep, causes superficial and visceral abscesses, mainly affects horses, causes ulcerative lymphangitis of the abdominal abscesses in the chest and abdomen, distal extremities and hematomas. The presence of these two types of biovar has been assured by bimolecular techniques (Connor et al., 2007). Caring for animals in veterinary clinics leads to an increased risk rate of MDR-organisms (MDROs) (Schmidt et al., 2020)

Antimicrobial resistance is an increasing problem for both humans and veterinarians and the issue that needs to be addressed in both related areas is a current policy priority. Attempts to decrease Antimicrobial Resistance (AMR) on farms have yet centered on controlling the supply and utilization of antimicrobial drugs. (Robert and Andrew, 2019).
The aim of this study is to find out the bacterial infection of some cases in farm animals suffering from wounds and abscesses in Fayoum Governorate, Egypt and related Antimicrobial Resistance (AMR) procedures and technical investigations focused on disinfectant effects or the effects of AMR on bacterial persistence

\section{Materials and Methods}

\section{Samples and Sampling}

The study was carried out in villages of Fayoum Governorate, Egypt during the period from march 2020 to march 2021. The owners of the studied animals are individual farmers every farmer had one or more species from cows, buffaloes, sheep, goats, donkeys and camel. The farmers are mainly keeping their animals with each other in the back yard of their house.

The samples were collected from 130 different animals (24 buffaloes, 6 cows,35 sheep, 40 goats, 10 camels and 15 donkeys). The sample from buffaloes were collected from edematous skin, 6 swabs from cows with eye pus, that from sheep, goats and camels were collected from abcessiated and caseating lymph nodes and that from donkeys were obtained from wounds at necks.

The study was designed as follow:

a. Swabs samples were collected from the studied farm animals suffer from abscesses and wound infection

b. All samples were submitted for isolation of bacteria followed by a susceptibility test for different antimicrobial agents

c. Study the effect of the used two disinfectants (Povidone-iodine (PI) 10 and $\mathrm{H}_{2} \mathrm{O}_{2} 1 \%$ ) on bacterial isolates and evaluation of disinfectant activity on Each Test Isolate by Time Killing assa

\section{Bacteriology Examination}

All samples from lymph nodes and edematous skin lesions were inoculated on trypticase soy broth (TSB) and incubated for 37C for $24 \mathrm{~h}$ (Jones and Collins, 1986).

All samples were cultured on duplicated blood agar (incubation at $37 ! \mathrm{C}$ for 24 to $48 \mathrm{~h}$ in complete aerobic conditions supported with $10 \% \mathrm{CO}_{2}$ ), MacConkey agar, Pseudomonas agar, mannitol salt agar (incubation for $24 \mathrm{~h}$ at $37^{\circ} \mathrm{C}$ ) (Quinne et al., 2002)

All suspected colonies were put forward for Gram stainingand different biochemical identification tests (Quinne et al., 2002).

$\beta$ hemolytic colonies with golden yellow or pink on mannitol, Gram-positive grapes like cocci were examined for catalase test, oxidase and confirmed the identification by using S.R.O GP24 for identification of Staphylococcus spp. and Streptococcus spp. 
Table 1: List of antimicrobial disks used

\begin{tabular}{llc}
\hline Name of antibiotic & Code of disc & Conc/ $\mu \mathrm{g}$ \\
\hline Penicillin & P & 10 \\
Oxacillin & OX & 1 \\
Ampicillin & AMP & 10 \\
Ampicillin-sulbactam & SAM & 20 \\
Ampicillin -clavulanic acid & AMC & 30 \\
Piperacillin-tazobactam & TZP & 110 \\
Cephalexin & CL & 30 \\
Cephradine & CE & 30 \\
Cefotaxime & CTX & 30 \\
Cefoperazone & CFP & 75 \\
Meropenem & MEM & 10 \\
Aztreonam & ATM & 300 \\
Clarithromycin & CLR & 10 \\
Erythromycin & E & 15 \\
Oxytetracycline & OT & 30 \\
Chloramphenicol & C & 30 \\
Norfloxacin & NO & 10 \\
Ofloxacin & OFX & 5 \\
Lomefloxacin & LOM & 10 \\
Kanamycin & K & 30 \\
Novobiocin & NV & 30 \\
Amikacin & AK & 30 \\
Linezolid & LZD & 30 \\
Clindamycin & DA & 2 \\
\hline & &
\end{tabular}

Hemolytic colonies and non-hemolytic creamy in color on blood agar and in trypticase soy broth, it forms a surface film, though the culture remains clear; this film is broken by agitation, forming flakes were submitted for catalase, oxidase and confirmed for Corynebacterium species by S.R.O GP24.

Blueish green colonies on P. eudomonas agar, Gramnegative small bacilli, were examined for oxidase test and confirmed identification for $P$. aeruginosa by using S.R.O. GN24.

\section{Susceptibility Disc Diffusion Test Against Different Antimicrobial Agents}

In relation to the characters of antimicrobial agent used were listed in Table (1). Each culture tested is plotted on a non-inhibitory agar medium (brain heart infusion agar, blood agar or try ptone soy agar) After incubation at $35^{\circ} \mathrm{C}$ overnight, 4 or 5 well-isolated colonies were selected with an inoculating needle or loop and Transfer the broth and vortex Mueller-Hinton completely, incubate the broth at $35^{\circ} \mathrm{C}$ until turbid, then adjust the turbidity to the appropriate density by comparing the standard 0.5 McFarland tube. During $15 \mathrm{~min}$ after checking the turbidity of the inoculum suspension,

A sterile cotton swab dipped in suspension. Pressing firmly on the inner wall of the tube just above the liquid level. The swab was trimmed over the entire surface of the medium three times, rotating the plate about $60^{\circ}$ after each application to ensure even distribution of the inoculum.
Antimicrobial discs were placed on plates as soon as possible, but not more than 15 minutes after inoculation. Place the discs individually with sterile forceps, then gently tap the agar. After the plate was inverted and incubated at $35^{\circ} \mathrm{C}$ for 16 to $18 \mathrm{~h}$ (CLSI, 2012). The diameter of the zones of complete inhibition was measured (including the diameter of the disk) and recorded in millimeters. The measurements were made with a ruler on the undersurface of the plate without opening the lid according to CLSI (2017).

\section{Evaluation of Disinfectant Activity on Each Test Isolate by Time Killing Assay}

Ten of each isolate except $C$. equi ( 8 isolates) working inoculum was prepared by diluting overnight cultures with sterile water to match their turbidity to the 0.5 McFarland standard (A595 0.06-0.08) which contained approximately $1-2 \times * 10^{8} \mathrm{CFU} / \mathrm{mL}^{-1}$ (NCLS 1996, Jorgensen at al., 1999). The McFarland 0.5-turbidity bacterial suspensions were additional diluted with Muller Hinton Broth (MHB) to obtain $1 \times * 10^{6}$ for antibacterial assays. Povidone-iodine(PI) $10 \%$ as a broad antiseptic for external use of animals and $\mathrm{H}_{2} \mathrm{O}_{2} 1 \%$ in water for routine use used in this study.

An aliquot of bacterial suspensions $(1 \mathrm{~mL})$ prepared as described above $\left(1 \times * 10^{6} \mathrm{CFU} / \mathrm{mL}\right)$ was incubated with $1 \mathrm{~mL}$ of the disinfectant agents alone (PI and $\mathrm{H}_{2} \mathrm{O}_{2}$ ), at $37^{\circ} \mathrm{C}$. A sample of $100 \mu \mathrm{L}$ was taken every $4 \mathrm{~h}$ up to $24 \mathrm{~h}$ and subsequently measured for the bacterial growth by reading the OD595 $\mathrm{nm}$ (Chusri et al. 2014).

\section{Results and Discussion}

Eight isolates $(33.3 \%)$ of $C$. equiwas isolated only from buffalo with edematous skin lesions (OSD), while $C$. oviswere isolated from sheep and goats with caseouslymphadenitis lesions at a rate of $28.6 \%$ and $27.5 \%$ respectively (Table 2). The isolates were nonhemolytic cream-colored colonies on sheep blood agar, in trypticase soya broth, the surface film is formed, though the culture still clear; this film is broken by agitation, forming flakes, the isolates were catalase positive and oxidase negative and confirmed identified by S.R.O. GP24.

In Egypt, (Arafa et al., 2019) showed that serotype II ( $C$. equi) was the cause of OSD in buffalo. The reason why buffalo is not affected by the nitrate-negative serotype $\mathrm{I}(C$. ovis) organism under natural conditions is unknown.

Corynebacterium pseudotuberculosis $(C$. ovis) is a common cause of the bacterial disease caseous lymphadenitis which occurs in goats, sheep, cattle, buffalo and horses. The morphological and biochemical characteristics Nitrate reductase production was determined the identification of $C$. pseudotuberculosis was used by Sellyei et al. (2017) to distinguish the equi biovar (isolated from horses and cattle; nitrate reduction 
positive) from the ovis biovar (isolated from sheep and goats; nitrate reduction negative), Dorella et al. (2006).

The occurrence of caseous lymphadenitis in Egypt can increase the participation of goats and sheep in the national animal husbandry and its relationship to the effect of this disease. The economic losses include low milk production, loss weight gain, decreased value of skins due to scarring and the high value of treatment of superficial abscesses. When animals affected in critical areas of lymph nodes (jaw, groin area, udder) the losses were increased (Guimarães et al., 2011; Osman et al., 2018) .

The highest rate of Staphylococcus aureus (S. aureus) isolates was observed in the wound of donkeys and eye lesion of cows $(66.7 \%)$ followed by camel $60 \%$; goats $22.5 \%$ and it was nearly similar in sheep and buffalo (8.6 and $8.3 \%$ respectively) Tiwari, (2016) recorded the highest rate of $S$. aureus isolation was from equine wound followed by cattle and buffalo. The isolates were characterized by $\beta$ hemolysis on blood agar, golden yellow colonies on mannitol agar, Gram-positive grapes like colonies and confirmed by S.R.O. GP24.

According to the above definitions, S. aureus can be classified as an opportunistic disease for both human and animals. The composition of natural flora depends on the organism on the species, forage and the environment, including population density. Nevertheless, S. aureus is the most frequently isolated coagulase-positive Staphylococcus (CPS) from the anterior nares and temporarily from the skin of humans and animals. (Bierowiec et al., 2016).

On the other hand, the total isolates of P. aeruginosa were $32(24.6 \%)$ this result is nearly similar to Tiwari (2016). P. aeruginosa was highly isolated from donkeys followed by sheep, cows, goats, camel and buffalo in a rate of $80 ; 33.3 ; 31.4 ; 255 ; 20$ and $8.3 \%$ respectively. The isolates were bluish-green on pseudomonas specific media, oxidase-positive and confirmed by S.R.O. GP24. Saha et al. (2019) reported the rate of $P$. aeruginosawas $15 \%$ for cattle and goats and 5\% for sheep. Devrajanid et al. (2010) isolated $P$. aeruginosa and $S$. aureus from wounds in camel at a rate of $10.52 \%$.

On a susceptibility test against antimicrobial agents (Table 3), Piperacillin-tazablam was the best of choice for $P$. aeruginosa and C. equi (20\%). Many of the members of the Enterobacteriaceae, including Klebsiella spp. and Pseudomonas Are Inhibited by Piperacillin. It is given by intramuscular or intravenous injection and is widely distributed in body fluids and tissues. Like other newer penicillins, it's been accredited for serious infection caused by susceptible strains of specific organisms in intra-abdominal, urinary tract, gynecologic, decrease respiratory tract, skin structure, bone and joint and gonococcal infections and septicemia (Young and Plosker, 2001). It was found that $P$. aeruginosais resistant to the rest of the antibacterial agents. P. aeruginos $a$ is intrinsically resistant to many antimicrobial classes because of the presence of numerous efflux pumps in its cell wall and cell membrane. Upregulation of those efflux pumps results in resistance to the limited range of effective agents; $P$. aeruginosa is widely recognized for its capacity to become resistant during treatment. It also can become resistant to $\beta$-lactams viaporin loss and the purchase of $\beta$-lactamases (AURA, 2019).

Methicillin-resistant $S$. aureus (MRSA) isolates that showed resistance to multiple drug resistance to a high number of antibacterial agents as penicillins, methicillin (oxacillin), $\beta$-lactam; macrolides and aminoglycosides antibiotics. In the present study, $S$. aureus was resistant to all classes of antibiotic classes used except phencols and fluoroquinolones were they sensitive at a rate of $13.3 \%$ to lomefloxacin and $6.7 \%$ to chloramphenicol (Table 3). Chloramphenicol is an artificial broad-spectrum antibioticIt is a rarely used drug for its known severe adverse effects and it was indicated to be used superficially as bacterial conjunctivitis (Oong and Tadi 2020). Tiwari et al. (2016) reported that MRSA was isolated from wounds of farm animals and accomplice animals.

The Povidone iodine is a beneficial preoperative decolonizing agent for the prevention of $\mathrm{S}$. aureus infections which includes MRSA. Lepelletier et al. (2020). Iodine and iodophorsarea highly virucidal, bactericidal, tuberculocidal, sporicidal and fungicidal. Although aqueous or alcoholic (tincture)solutions of iodine are related to irritation and excessivestaining and aqueous solutions are generally unstable. Overcome these problems by developing iodine carriers. Iodophors Consists of complexes of iodine and a solubilizing agent, which acts as a pool of the active "free" iodine (Hobosyan et al., 2012). Hydrogen peroxide $\left(\mathrm{H}_{2} \mathrm{O}_{2}\right)$ is an external antiseptic used in wound cleaning which kills pathogens by oxidation eruption and local oxygen production Zhu et al. (2017).

In the present study, Fig. (1) showed the bacterial growth at OD595 after treatment with PI 10\% at different time intervals, all types of isolates showed the lowest growth after $24 \mathrm{~h}, C$. ovis showed the lowest bacterial growth. Figure (2) showed the bacterial growth at OD595 after treatment with $\mathrm{H}_{2} \mathrm{O}_{2} 1 \%$ at different time intervals, also types of isolates showed the lowest growth after 24 h, $C$. equi showed the lowest bacterial growth.

The presence of Bacterial growth in all treated isolates till exposure to treatment for $24 \mathrm{~h}$ proved the tolerance of these clinical isolates which ranged from $75-30 \%$ in treatment with PI and from70-50 in treatment with $\mathrm{H}_{2} \mathrm{O}_{2}$ 
(Table 4). Show C. equi and C. ovis highest for tolerance to PI (75\&0\% respectively), while $S$. aureus showed the highest rate of tolerance to $\mathrm{H}_{2} \mathrm{O}_{2}(70 \%)$. These results agree with Aksoy et al. (2020). Who reported that $\mathrm{H}_{2} \mathrm{O}_{2}$ is the strongest disinfectant followed by glutaraldehyde and iodine when exposed to 3 types of salmonella. The killing activity of disinfectants is depends upon 3 factors including the concentration of treatment, temperature and treatment period also, from our opinion concentration of clinical isolates plays a role.

Antibiotic resistances are classified into Multidrug Resistant (MDR) which isn't susceptible to at least one representative from every of three classes of selected antimicrobial compound families (El Zowalaty et al. 2015; Fodor et al., 2020). Extreme or extensively Drug-Resistant (XDR) is not susceptible to at least a single representative of all but very few classes of antimicrobial compound families. Pan-drug resistant (PDR) is not susceptible to any of the tested or empirical representatives of all acknowledged antimicrobial compound families (El Zowalaty et al., 2015). MDR and PDR isolates are inconsistent in medical literature, disqualifying reliable comparison of data. To reach a standardized definition, we applied the multidrug resistance definition from human medicine (Magiorakos et al., 2012). This adaption was limited by the unattainability of certain susceptibility results and differing antimicrobial agents in human and veterinary medicine. Therefore, the establishment of a standard definition of MDR bacteria in veterinary medicine should be supported.

The prevalence, phenotypic resistance pattern and diversity of the four clinical isolates (randomly 10 isolates of each strain except $8 C$. equi isolates were used) are recorded in (Table 5). They were tested for their resistance phenotypic profile against 24 antibiotics representing 9 classes. This diversity of both Gram-ve bacteria and Gram +ve bacteria isolated from skin lesions reflect the capacity of AMR revealed the haphazard and extensive use of antibiotics which has led to the emergence and extent spread of resistant pathogenic bacteria (Wolska et al. 2012; Garza-Cervantes et al., 2020). Also, Table (5) showed the tolerance of each isolate to PI and H2O2, where most PDR isolates showed tolerance to both PI and $\mathrm{H} 2 \mathrm{O} 2$. The risk of MDR and PDR strains on antiseptic and disinfectants effect was observed in this study (Fig. 3). Although antiseptics have broader spectrums of antimicrobial activity than antibiotics and a much lower risk of selecting bacterial resistance and Lachapelle et al. (2013) pronounced that antiseptics are consequently suitable alternatives to antibiotics for the control of localized superficial skin infections. George (1996) provides numerous examples of MDR systems in which an operon or gene is associated with changes in antiseptic or disinfectant susceptibility. Also, Mycock (1985) said that MRSA strains showed a remarkable increase in intolerance (at least 5,000-fold) to povidone-iodine.

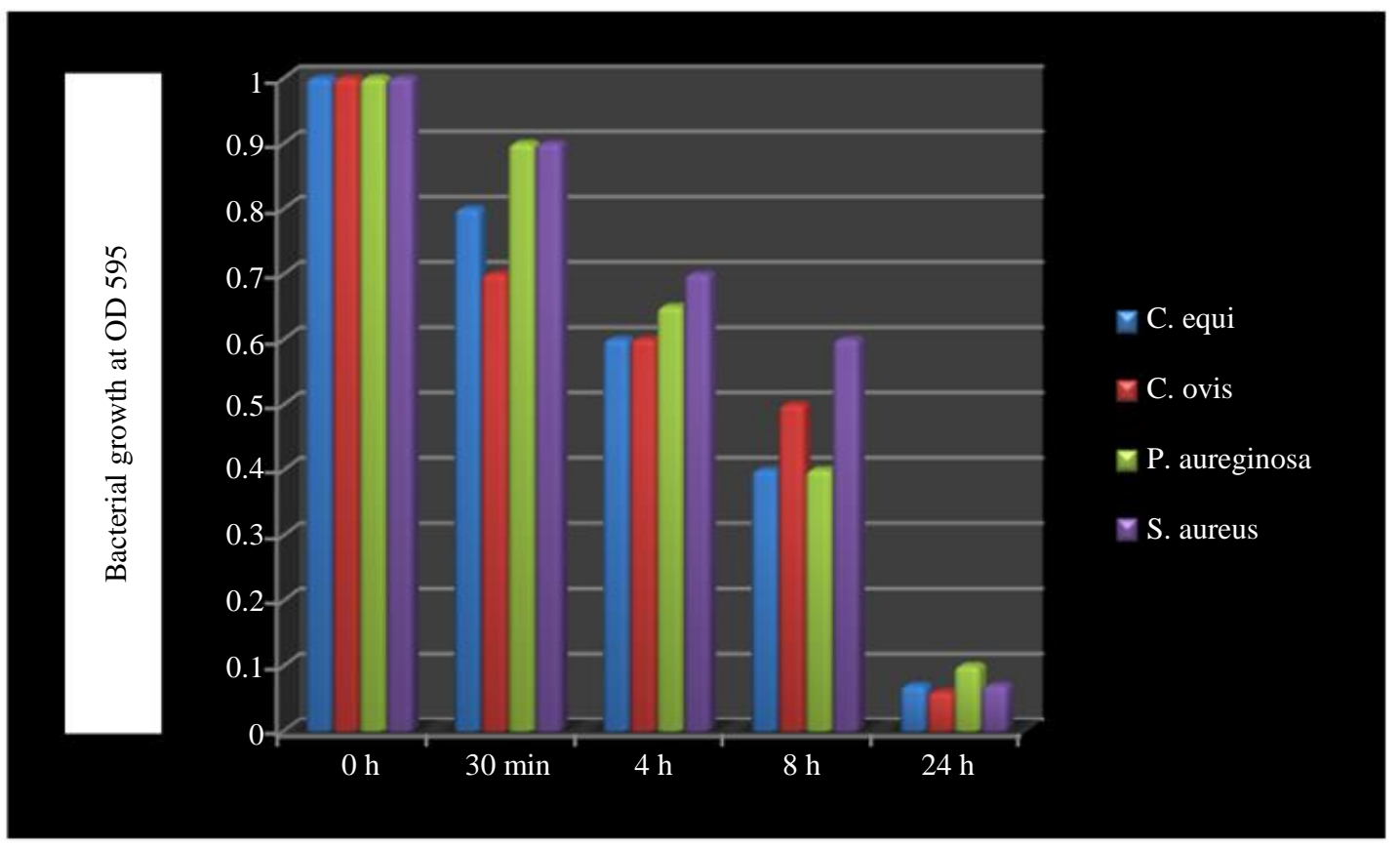

Fig. 1: Bacterial growth of isolates after treatment with PI 10\% using time killing assay 


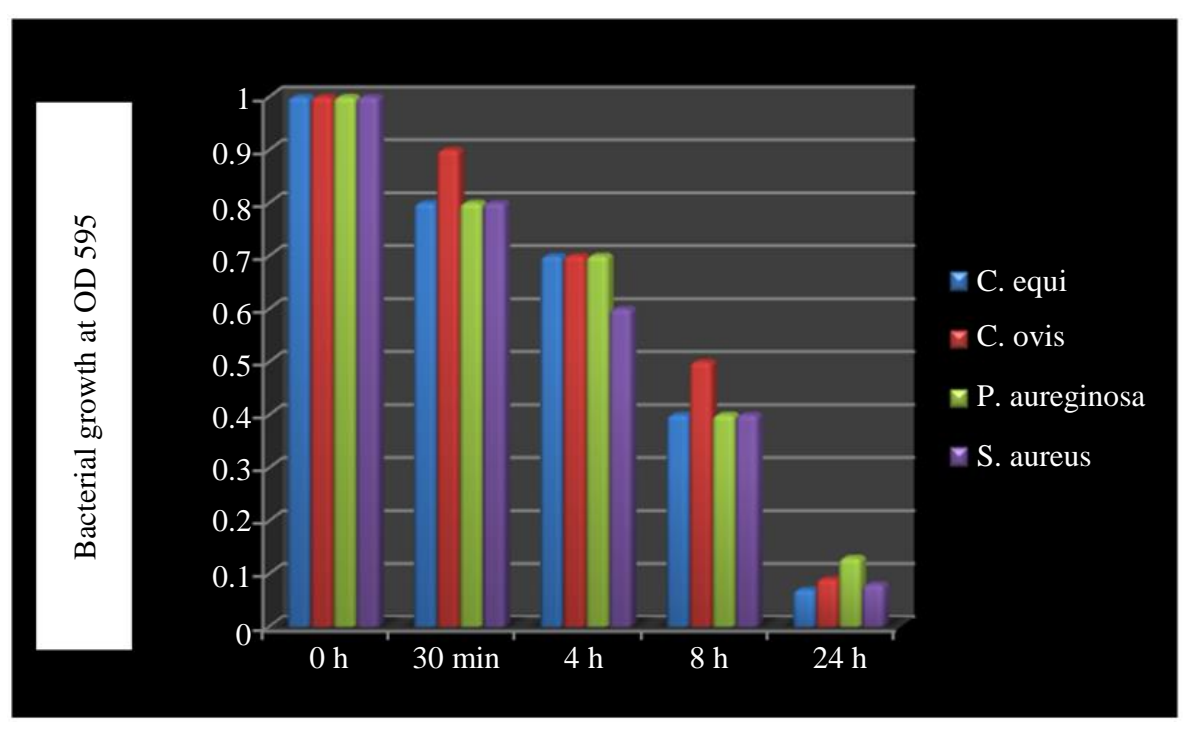

Fig. 2: Bacterial growth of isolates after treatment with $\mathrm{H} 2 \mathrm{O} 21 \%$ using time killing assay

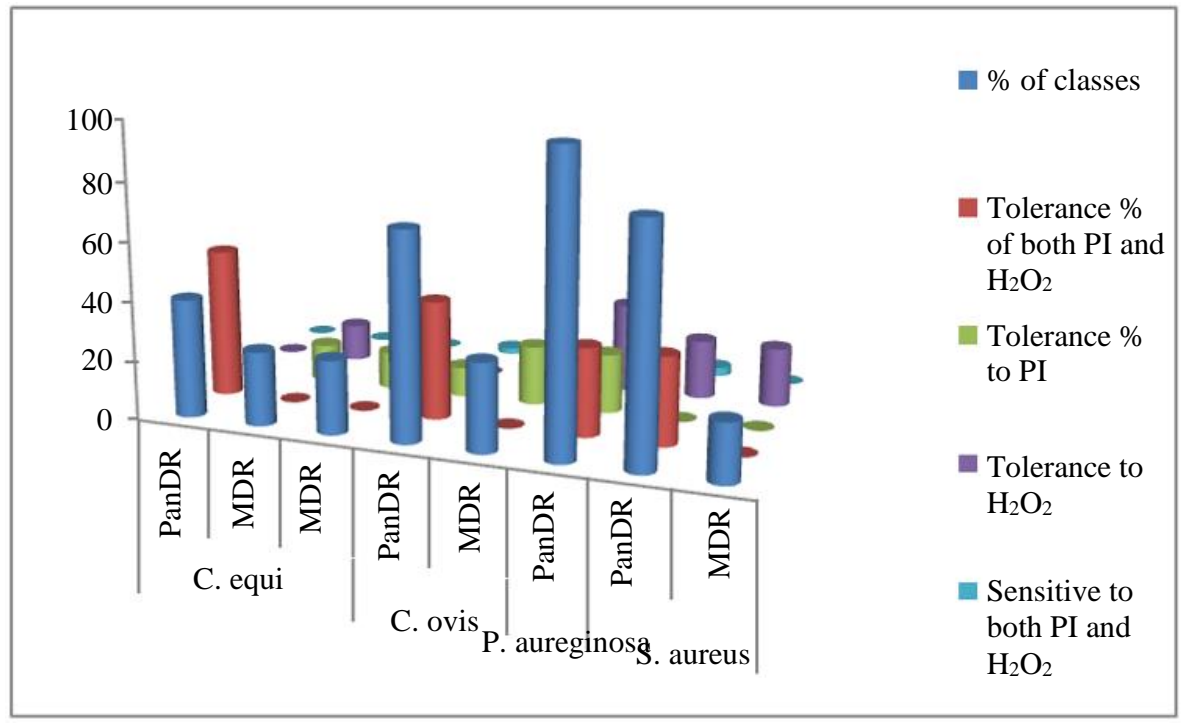

Fig. 3: The relationship between type of antimicrobial resistance patterns and tolerance to $\mathrm{PI}$ and $\mathrm{H}_{2} \mathrm{O}_{2}$

Table 2: Rate of different isolates obtained from different animal species

\begin{tabular}{|c|c|c|c|c|c|c|c|c|c|c|}
\hline \multirow[b]{3}{*}{$\begin{array}{l}\text { Source of } \\
\text { samples }\end{array}$} & \multirow{3}{*}{$\begin{array}{l}\text { Type of } \\
\text { samples }\end{array}$} & \multirow{3}{*}{$\begin{array}{l}\text { No. of } \\
\text { samples }\end{array}$} & \multicolumn{8}{|c|}{ Type of isolates } \\
\hline & & & \multicolumn{2}{|c|}{ C. equi } & \multicolumn{2}{|c|}{ C. ovis } & \multicolumn{2}{|c|}{ S. aureus } & \multicolumn{2}{|c|}{ P. aerugenosa } \\
\hline & & & No. & $\%$ & No & $\%$ & No. & $\%$ & No. & $\%$ \\
\hline Buffalo & Edematous skin & 24 & 8 & 33.3 & 0 & 0 & 2 & 8.3 & 2 & 8.3 \\
\hline Cows & Eye swab & 6 & 0 & 0 & 0 & 0 & 4 & 66.7 & 2 & 33.3 \\
\hline Sheep & L.n & 35 & 0 & 0 & 10 & 28.6 & 3 & 8.6 & 11 & 31.4 \\
\hline Goat & L.n & 40 & 0 & 0 & 11 & 27.5 & 9 & 22.5 & 10 & 25 \\
\hline Camel & L.n & 10 & 0 & 0 & 2 & 20 & 6 & 60 & 2 & 20 \\
\hline \multirow[t]{2}{*}{ Donkeys } & neck wounds & 15 & 0 & 0 & 0 & 0 & 10 & 66.7 & 5 & 80 \\
\hline & Total & 130 & 8 & 6.2 & 23 & 17.7 & 34 & 26.2 & 32 & 24.6 \\
\hline
\end{tabular}


Table 3: Susceptibility test results against different antibiotic agents

\begin{tabular}{|c|c|c|c|c|c|c|c|c|c|c|c|c|}
\hline \multirow[b]{2}{*}{ Antibacterial agents } & \multicolumn{3}{|c|}{ P.aeruginosa * } & \multicolumn{3}{|c|}{ S.aureus } & \multicolumn{3}{|c|}{ C.equi } & \multicolumn{3}{|c|}{ C.ovis } \\
\hline & $\mathrm{S}$ & I & $\mathrm{R}$ & $\mathrm{S}$ & I & $\mathrm{R}$ & $\mathrm{S}$ & I & $\mathrm{R}$ & $\mathrm{S}$ & I & $\mathrm{R}$ \\
\hline \multicolumn{13}{|l|}{ Penicillins } \\
\hline Penicillin & $\begin{array}{l}0 \\
73.3\end{array}$ & 0 & 100 & 0 & 0 & 100 & 0 & 25 & 75 & 26.7 & 0 & \\
\hline Oxacillin & 0 & 0 & 100 & 0 & 0 & 100 & - & - & - & - & - & - \\
\hline $\begin{array}{l}\text { Ampicillin } \\
\beta \text {-Lactam/ } \beta \text {-Lactamase } \\
\text { Inhibitor Combinations }\end{array}$ & 0 & 0 & 100 & 0 & 0 & 100 & 0 & 0 & 100 & 0 & 0 & 100 \\
\hline Ampicillin-subactam & 0 & 26.7 & 73.3 & 0 & 26.7 & 73.3 & 0 & 0 & 100 & 0 & 0 & 100 \\
\hline Ampicillin -clavulanic acid & 0 & 0 & 100 & 0 & 0 & 100 & 0 & 0 & 100 & 0 & 0 & 100 \\
\hline Pipracillin-tazablam & 20 & 0 & 80 & 0 & 0 & 100 & 20 & 0 & 80 & 0 & 0 & 100 \\
\hline \multicolumn{13}{|l|}{ Cephems } \\
\hline Cephalexin & 0 & 0 & 100 & 0 & 0 & 100 & 0 & 0 & 100 & 0 & 0 & 100 \\
\hline Cephradine & 0 & 20 & 80 & 20 & 0 & 80 & 0 & 0 & 100 & 0 & 0 & 100 \\
\hline Cefotaxam & 0 & 0 & 100 & 0 & 0 & 100 & 0 & 0 & 100 & 0 & 0 & 100 \\
\hline Cefoperazon & 0 & 0 & 100 & 0 & 0 & 100 & 0 & 0 & 100 & 0 & 0 & 100 \\
\hline Cefquinome & 0 & 0 & 100 & 0 & 0 & 100 & 0 & 0 & 100 & 0 & 0 & 100 \\
\hline \multicolumn{13}{|l|}{ Monobactam } \\
\hline Meropenem & 0 & 0 & 100 & 0 & 0 & 100 & 0 & 0 & 100 & 0 & 0 & 100 \\
\hline Aztreonam & 0 & 0 & 100 & 0 & 0 & 100 & 0 & 0 & 100 & 0 & 0 & 100 \\
\hline \multicolumn{13}{|l|}{ Macrolides } \\
\hline Clarithromycin & 0 & 0 & 100 & 0 & 0 & 100 & 0 & 0 & 100 & 0 & 0 & 100 \\
\hline Erythromycin & 0 & 0 & 100 & 0 & 0 & 100 & 0 & 0 & 100 & 0 & 0 & 100 \\
\hline \multicolumn{13}{|l|}{ Tetracyclines } \\
\hline Oxytetracyclin & 0 & 0 & 100 & 0 & 26.7 & 73.3 & 8.3 & 0 & 91.7 & 0 & 0 & 100 \\
\hline \multicolumn{13}{|l|}{ Phenicols } \\
\hline Chloramphenicol & 0 & 0 & 100 & 6.7 & 0 & 93.3 & 0 & 0 & 100 & 0 & 0 & 100 \\
\hline \multicolumn{13}{|l|}{ Fluoroquinolones } \\
\hline Norfloxacin & 0 & 0 & 100 & 0 & 26.7 & 73.3 & 0 & 0 & 100 & 0 & 0 & 100 \\
\hline Ofloxacin & 0 & 0 & 100 & 0 & 26.7 & 73.3 & 0 & 0 & 100 & 0 & 0 & 100 \\
\hline Lomofloxacin & 0 & 0 & 100 & 13.3 & 0 & 86.7 & 0 & 0 & 100 & 0 & 0 & 100 \\
\hline \multicolumn{13}{|l|}{ Aminoglycosides } \\
\hline Kanamycin & 0 & 0 & 100 & 0 & 20 & 80 & 0 & 0 & 100 & 0 & 0 & 100 \\
\hline Novobiocin & 0 & 0 & 100 & 0 & 0 & 100 & 0 & 0 & 100 & 0 & 0 & 100 \\
\hline Streptomycin & 0 & 0 & 100 & 0 & 0 & 100 & 0 & 0 & 100 & 0 & 0 & 100 \\
\hline Neomycin & 0 & 0 & 100 & 0 & 0 & 100 & 0 & 0 & 100 & 0 & 0 & 100 \\
\hline Amykacin & 0 & 0 & 100 & 0 & 26.7 & 73.3 & 0 & 0 & 100 & 0 & 0 & 100 \\
\hline \multicolumn{13}{|l|}{ Oxazolidinones } \\
\hline Linezolid & 0 & 0 & 100 & 0 & 0 & 100 & 33.3 & 0 & 66.6 & 40 & 0 & 60 \\
\hline \multicolumn{13}{|l|}{ Lincosamides } \\
\hline Clindamycin & 0 & 0 & 100 & 0 & 6.7 & 93.3 & 0 & 0 & 100 & 0 & 0 & 100 \\
\hline
\end{tabular}

*Results were recorded in percentage (-): Not applied S: Sensitive I: Inermediete R: rESISTENCE

Table 4: The rate of tolerance of different isolates to disinfectants

\begin{tabular}{|c|c|c|c|c|c|c|c|c|}
\hline \multirow[b]{2}{*}{ Disinfectant } & \multicolumn{2}{|c|}{ C. equi } & \multicolumn{2}{|c|}{ C. ovis } & \multicolumn{2}{|c|}{ P. aeruginosa } & \multicolumn{2}{|c|}{ S. aureus } \\
\hline & No. & $\%$ & No. & $\%$ & No. & $\%$ & No. & $\%$ \\
\hline PI 10\% & 6 & 75 & 7 & 70 & 5 & 50 & 3 & 30 \\
\hline $\mathrm{H}_{2} \mathrm{O}_{2} 1 \%$ & 6 & 60 & 5 & 50 & 6 & 60 & 7 & 70 \\
\hline
\end{tabular}




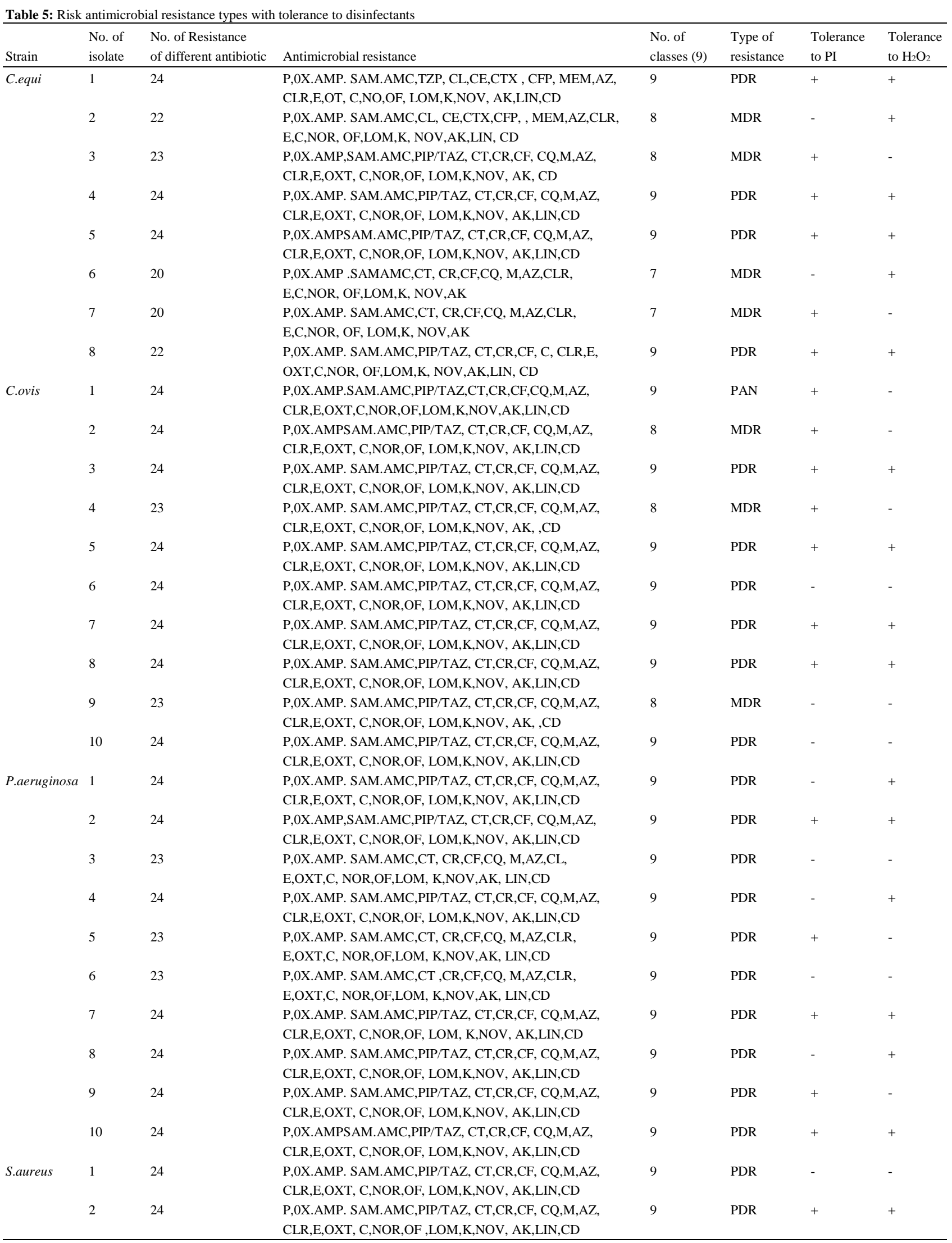




\begin{tabular}{|c|c|c|c|c|c|c|}
\hline 3 & 24 & $\begin{array}{l}\text { P,OX.AMP. SAM.AMC,PIP/TAZ, CT,CR,CF, CQ,M,AZ, } \\
\text { CLR,E,OXT, C,NOR,OF, LOM,K,NOV, AK,LIN,CD }\end{array}$ & 9 & PDR & + & + \\
\hline 4 & 24 & $\begin{array}{l}\text { P,OX.AMP. SAM,AMC,TZP, CL,CE,CEP, CEQ,MEM,AZ, } \\
\text { CLR,E,OT, C,NO,OFX, LOM,K,NV, AK,LIN,DA }\end{array}$ & 9 & PDR & + & + \\
\hline 5 & 23 & $\begin{array}{l}\text { P,OX.AMP. SAM.AMC,TZP, CL,,CE,CEQ, MEM,AZ,CLR, } \\
\text { E,OT,C, NO,OFX,LOM ,K,NV,AK, LIN,DA }\end{array}$ & 9 & PDR & - & + \\
\hline 6 & 23 & $\begin{array}{l}\text { P,OX.AMP. SAM.AMC,TZP, CL,CE,CTX CEQ,MEM,AZ, } \\
\text { LR,E,OT, C,NO,OFX, K,NV,AK, LIN,DA }\end{array}$ & 9 & PDR & - & - \\
\hline 7 & 23 & $\begin{array}{l}\text { P,OX.AMP. SAM.AMC,TZPZ, CL,CE,CTX, CEQ,MEM,AZ, } \\
\text { CLR,E,OT, C,NO,OFX, K,NV,AK, LIN,DA }\end{array}$ & 9 & PDR & - & + \\
\hline 8 & 22 & $\begin{array}{l}\text { P,OX.AMP. SAM.AMC,TZPZ, CL,CTX,CEQ, M,AZ,CLR, } \\
\text { E,OT,C, NO,OF, K, NV,AK,LIN, DA }\end{array}$ & 7 & MDR & - & + \\
\hline 9 & 23 & $\begin{array}{l}\text { P,OX.AMP, SAM.AMC,TZP, CL,CE,CTX, CEQ,MEM,AZ, } \\
\text { CLR,E,OT, C,NO,OFX, K,NV,AK, LIN,CD }\end{array}$ & 9 & PDR & - & - \\
\hline 10 & 22 & $\begin{array}{l}\text { P,OX.AMP. SAM.AMC,TZP, CTX,CF,CEQ, MEM,AZ,CLR, } \\
\text { E,OT,C, NO,OFX, K, NV,AK,LIN, DA }\end{array}$ & 7 & MDR & - & + \\
\hline
\end{tabular}

$\mathrm{CL}=$ Cephalexin, $\mathrm{OX}=$ oxacillin, $\mathrm{SAM}=$ ampicillin/sulactam, $\mathrm{AMP}=$ ampicillin, $\mathrm{AMC}=\mathrm{Apmpicillin} /$ clavulinic acid, $\mathrm{TZP}=\mathrm{Pipracillin}-\mathrm{tazablam}, \mathrm{P}=$ penicillin, $\mathrm{CTX}=$ Cefotaxam, $\mathrm{CE}=$ Cephradine, $\mathrm{CEQ}=$ Cefquinome, $\mathrm{CEP}=$ Cefoperazone $\mathrm{MEM}=$ Meropenem, $\mathrm{CLR}=$ Clarithromycin, $\mathrm{AZ}=\mathrm{Aztreonam}, \mathrm{E}=\mathrm{Erythromycin}, \mathrm{C}=\mathrm{Chloramphenicol}$, OT = Oxytetracycline, OFX = Ofloxacin, NO = Norfloxacin, $\mathrm{K}=$ kanamycin, $\mathrm{LOM}=$ Lomefloxacin, AK = Amikacin, NV = Novobiocin,DA = Clindamycin LIN = Linezolid

\section{Conclusion}

Caseous lymphadenitis is still an important challenge for sheep and goat industries, limiting their productivity. The forceful market and movement of small ruminants, without the necessary biosecurity measures, are important problems to the control of caseous lymphadenitis, maintaining its frequency at high levels; $C$. equi also plays a role in buffalo raring as causing edematous skin disease which affects milk and meat production. as well as the high resistance of both C. ovis and C. equi to antibiotics and disinfectants which indicates that specific control measures should be adopted. Thus, great efforts need to be made by all responsible persons in sheep and goat industries and buffalo raring to control these terrible diseases. MRSA, as well as PDR Pseudomonas aeruginosa, were observed animal wounds which prove the bad hygiene. Increasing contact time is more effective against the microbe.

\section{Acknowledgement}

We would like to thank evryone in Animal Health Research Istituite (AHRI) Agriculture Research Center (ARC) for helping and supporting us

\section{Author's Contributions}

Sultan Farag Nagati: Sample collection, bacteriological examination, writing the paper, editing, revising the manuscript and Corresponding Author.

Soumaya, El Shafii: Bacteriological examination and data analysis- writing the paper.

Shaimaa Abd EIMawgoud: Bacteriological examination and data analysis

\section{Ethics Approval}

The research protocol has been approved by Ethics Committee of experimental and clinical studies at Animal Health Research Institute (AHRI), Egypt. Approval number (167638).

\section{References}

Ahmed, M. I., Tijjani, A. N., \& Mustapha, A. R. (2008). Survey for common diseases and management practices of donkeys (Equus asinus) in Borno, State Nigeria. Nigerian Veterinary Journal, 29(3), 1-5. file:///C:/Users/zonera/Downloads/3597-

Article\%20Text-71371-1-10-20090108.pdf

Arafa, M. I, Hamouda, S. M., Rateb, H. Z., Abdel-Hafeez, M. M., \& Aamer, A. A. (2019). Oedematous Skin Disease (OSD) Transmission among Buffaloes. Global Journal of Medical Research:G Veterinary Science and Veterinary Medicine Volume 19 Issue 1 Version 1.0.

AURA. (2019). Third Australian report on antimicrobial use and resistance in human health..Published by the Australian Commission on Safety and Quality in HealthCareWebsite:

https://www.safetyandquality.gov.au/antimicrobialuse-and-resistance-in-australia/

Bierowiec, K., Płoneczka-Janeczko, K., \& Rypuła, K. (2016). Is the colonisation of Staphylococcus aureus in pets associated with their close contact with owners? PLoS One, 11(5), e0156052. https://journals.plos.org/plosone/article?id=10.1371/ journal.pone. 0156052

Bogale, B., Sisay, Z., \& Chanie, M. (2012). Strongyle nematode infections of donkeys and mules in and around Bahirdar, Northwest Ethiopia. http://213.55.79.198/xmlui/bitstream/handle/Researc $\mathrm{h} / 225 / 22 \% 20$ Basaznew\%20Zelalem\%20Mersha.pdf ?sequence $=1 \&$ isAllowed $=\mathrm{y}$ 
Chusri, S., Chongsuvivatwong, V., Rivera, J. I., Silpapojakul, K., Singkhamanan, K., McNeil, E., \& Doi, Y. (2014). Clinical outcomes of hospitalacquired infection with Acinetobacter nosocomialis and Acinetobacter pittii. Antimicrobial agents and chemotherapy, 58(7), 4172-4179. https://journals.asm.org/doi/abs/10.1128/AAC.02 992-14

Connor, K. M., Fontaine, M. C., Rudge, K., Baird, G. J., \& Donachie, W. (2007). Molecular genotyping of multinational ovine and caprine Corynebacterium pseudotuberculosis isolates using pulsed-field gel electrophoresis. Veterinary research, 38(4), 613-623. https://www.vetres.org/articles/vetres/abs/2007/04/v 07041/v07041.html

Davies, R., \& Wales, A. (2019). Antimicrobial resistance on farms: a review including biosecurity and the potential role of disinfectan. https://onlinelibrary.wiley.com/doi/full/10.1111/1 541-4337.12438

Devrajani, K., Abubakar, M., Fazlani, S. A., Shahid, F., Ourban, A. S., \& Imran, R. (2010). Occurrence and prevalence of bacterial species as identified from camel wound. Inter. J. Agro Vet. Med. Sci, 4(4), 96-104. file:///C:/Users/zonera/Downloads/kamlapaper$11 \% 20(1) . p d f$

Dorella, F. A., Pacheco, L. G. C., Oliveira, S. C., Miyoshi, A., \& Azevedo, V. (2006). Corynebacterium pseudotuberculosis: microbiology, biochemical properties, pathogenesis and molecular studies of virulence. Veterinary research, 37(2), 201-218. https://www.vetres.org/articles/vetres/abs/2006/02/v60 18/v6018.html

El Zowalaty, M. E., Al Thani, A. A., Webster, T. J., El Zowalaty, A. E., Schweizer, H. P., Nasrallah, G. K., ... \& Ashour, H. M. (2015). Pseudomonas aeruginosa: arsenal of resistance mechanisms, decades of changing resistance profiles and future antimicrobial therapies. Future Microbiology, 10(10), 1683-1706. https://www.futuremedicine.com/doi/abs/10.2217/fmb. 15.48

Fodor, A., Abate, B. A., Deák, P., Fodor, L., Gyenge, E., Klein, M. G., ... \& Makrai, L. (2020). Multidrug Resistance (MDR) and collateral sensitivity in bacteria, with special attention to genetic and evolutionary aspects and to the perspectives of antimicrobial peptides-A review. Pathogens, 9(7), 522. https://www.mdpi.com/755396

Garza-Cervantes, J. A., Meza-Bustillos, J. F., ResendizHernández, H., Suárez-Cantú, I. A., Ortega-Rivera, O. A., Salinas, E., ... \& Morones-Ramírez, J. R. (2020). Re-sensitizing ampicillin and kanamycinresistant E. coli and S. aureus using synergistic metal micronutrients-antibiotic combinations. Frontiers in bioengineering and biotechnology, 8, 612. https://www.frontiersin.org/articles/10.3389/fbioe.2 020.00612/full
George, A. M. (1996). Multidrug resistance in enteric and other Gram-negative bacteria. FEMS microbiology letters, 139(1), 1-10. https://academic.oup.com/femsle/articleabstract/139/1/1/598075

Gichure, M., Onono, J., Wahome, R., \& Gathura, P. (2020). Analysis of the benefits and production challenges of working donkeys in smallholder farming systems in Kenya. Veterinary World, 13(11), 2346. https://www.ncbi.nlm.nih.gov/pmc/articles/PMC77502 20/

Guimarães, A., Filipe Borges Do Carmo, Rebeca Barbosa Pauletti, Nubia Seyffert, Dayana Ribeiro andrey Pereira Lage, Marcos Bryan Heinemann anderson Miyoshi, Vasco Azevedo, \&Aurora Maria Gouveia, 2011.Caseous lymphadenitis: epidemiology, diagnosis and control. Iioab-india open access vol. 2; issue 2; 33-43. https://www. Researchgate.net/publication/285967469

Hii, M., Liu, C. E., Lee, Y. L., Liu, W. L., Wu, P. F., Hsieh, M. H., ... \& Wang, F. D. (2019). Resistance rates of non-albicans Candida infections in Taiwan after the revision of 2012 Clinical and Laboratory Standards Institute breakpoints. Infection and drug resistance, 12, 235.

https://www.ncbi.nlm.nih.gov/pmc/articles/PMC6 338119/

Hobosyan, M., Kazansky, A., \& Martirosyan, K. S. (2012). Nanoenergetic composite based on I2O5/Al for biological agent defeat. In Technical proceeding of the 2012 NSTI nanotechnology conference and expo (pp. 599-602).

Jones, D. (1986). Irregular, nonsporing Gram-positive rods. Bergey's manual of systematic bacteriology, 1261-1434. https://ci.nii.ac.jp/naid/20001428380/

Jorgensen, J. H., Turnidge, J. D., \& Washington, J. A. (1999). Antibacterial susceptibility tests: dilution and disc diffusion methods. In Manual of clinical microbiology. 7th ed. Edited by Murray, P. R., Pfaller, M. A., Tenover, F. C. E. J., Baron, \& Yolken, R. H. ASM Press, Washington, D.C. pp. 1526-1543. https://ci.nii.ac.jp/naid/10019777527/

Lachapelle, J. M., Castel, O., Casado, A. F., Leroy, B., Micali, G., Tennstedt, D., \& Lambert, J. (2013). Antiseptics in the era of bacterial resistance: a focus on povidone iodine. Clinical Practice, 10(5), 579. https://www.silver47.eu/Pdf/antiseptics-in-the-eraof-bacterial-resistance-a-focus-on-povidoneiodine.pdf

Lepelletier, D., Maillard, J. Y., Pozzetto, B., \& Simon, A. (2020). Povidone iodine: properties, mechanisms of action, and role in infection control and Staphylococcus aureus decolonization. Antimicrobial agents and chemotherapy, 64(9), e00682-20. https://doi.org/10.1128/AAC.00682-20. 
Magiorakos, A. P., Srinivasan, A., Carey, R. B., Carmeli, Y., Falagas, M. E., Giske, C. G., ... \& Monnet, D. L. (2012). Multidrug-resistant, extensively drugresistant and pandrug-resistant bacteria: an international expert proposal for interim standard definitions for acquired resistance. Clinical microbiology and infection, 18(3), 268-281. https://www.sciencedirect.com/science/article/pii/S1 $198743 X 14616323$

Mekuria, S., \& Abebe, R. (2010). Observation on major welfare problems of equine in Meskan district, Southern Ethiopia. Livestock Research for Rural Development, 22(3), 1-15.

Molla, S. E., \& Gondar, E. (2015). Prevalence of gastro intestinal nematode parasitic infections of horses and donkeys in and around Kombolcha town. http://nadre.ethernet.edu.et/record/652/files/Samuel Engdaw.pdf

Mycock, G. 1985. Methicillin/antiseptic-resistant Staphylococcus aureus. Lancet ii:949-950. https://www.thelancet.com/journals/lancet/article/PI IS0140-6736(85)90881-5/fulltext

Oong GC. \&P.Tadi, 2020.Chloramphenicol. [Updated 2020 Jul 8]. In: StatPearls [Internet]. Treasure Island (FL): StatPearls Publishing; 2020 Jan. https://www.ncbi.nlm.nih.gov/books /NBK555966

Osman, A. Y. (2018). The epidemiology and pathophysiology of caseous lymphadenitis: A review. Journal of Veterinary Medicine and Research. https://agris.fao.org/agrissearch/search.do?recordID=US2019V00193

Quinn, P. J., Markey, B. K., Carter, M. E., Donnelly, J., \& Leonard, F. C. (2002). Veterinary Microbiology and Microbial Diseases. Black well scientific publications. Iowa State University Press, Ames, Iowa, USA, 2002. 536 pp. ISBN-10: 0-632-05525-1

Saha, T. K., Begum, F., Kabir, S. L., Islam, M. S., \& Khan, M. S. R. (2019). Characterization of bacterial isolates from skin lesions of sheep, goat and cattle in different rearing condition. Asian Journal of Medical and Biological Research, 5(2), 117-125. https://www.banglajol.info/index.php/AJMBR/articl e/view/42493
Schmidt, J. S., Kuster, S. P., Nigg, A., Dazio, V., Brilhante, M., Rohrbach, H., ... \& Willi, B. (2020). Poor infection prevention and control standards are associated with environmental contamination with carbapenemase-producing Enterobacterales and other multidrug-resistant bacteria in Swiss companion animal clinics. Antimicrobial Resistance \& Infection Control, 9(1), 1-13. https://doi.org/10.1186/s13756-020-00742-5

Sellyei, B., Bányai, K., Bartha, D., Hajtós, I., Fodor, L., \& Makrai, L. (2017). Multilocus Sequencing of Corynebacterium pseudotuberculosis Biotype Ovis Strains. BioMed research international, 2017. https://www.hindawi.com/journals/bmri/2017/176 2162/

Shrikhande, G. B., Rewatkar, S. G., Deshmukh, S. S., Maske, D. K., \& Raghorte, Y. M. (2009). The incidence of helminth parasites in donkeys. $\begin{array}{lll}\text { Veterinary } \quad \text { world, } 2(6), & 224 .\end{array}$ http://www.veterinaryworld.org/Vol.2/June/The\%20 Incidence $\% 20$ of $\% 20 \mathrm{Helminth} \% 20 \mathrm{Parasites} \% 20 \mathrm{in} \%$ 20Donkeys.pdf

Timothy, F. H., \& Bruno, B. (2021). Wound Classification. Treasure Island (FL): StatPearls Publishing; NCBI Bookshelf. http://creativecommons.org/licenses/by/4.0/

Tiwari, R.; Yadav, S.K. \&S. Singh 2016 Methicillin Resistant Staphylococcus aureus Isolated from Wounds of Livestock and Companion Animals of Uttar Pradesh India: A Preliminary StudyInternational Journal of Pharmacology, 12:821-829.

Wolska, K. I., Grzes, K., \& Kurek, A. (2012). Synergy between novel antimicrobials and conventional antibiotics or bacteriocins. Pol J Microbiol, 61(2), 95-104.

Young, M., \& Plosker, G. L. (2001). Piperacillin/Tazobactam. Pharmacoeconomics, 19(11), 1135-1175. https://link.springer.com/article/10.2165/00019053200119110-00006

Zhu, G., Wang, Q., Lu, S., \& Niu, Y. (2017). Hydrogen peroxide: a potential wound therapeutic target. Medical Principles and Practice, 26(4), 301-308. https://www.karger.com/Article/Abstract/475501 